\title{
CENTRALIDAD E IDENTIDAD LOCAL EN GEOGRAFÍAS HIPERESCALARES Las cartografías de las encrucijadas territoriales del sudeste ibérico
}

\author{
Autor: Miguel Huertas Fernández \\ Universidad de Granada. UGR. \\ Director de la tesis en curso: D. Alejandro Grindlay Moreno y D. Juan Luis Rivas Navarro. \\ Mail: miguel.hufer@gmail.com
}

\section{RESUMEN}

La investigación plantea una forma de generación de nuevas cartografías para los territorios despoblados y económicamente deprimidos del sudeste ibérico, que desvelan los lugares cargados de energía capaces de generar centralidad y desarrollo, y que preparan el territorio para la llegada de proyectos globales y refuerzan de manera recíproca las relaciones continentales con las identidades locales.

Palabras clave: hiperescala, encrucijada, identidad, corredor

\section{ABSTRACT}

The research proposes a way of generating new maps for unpopulated and economically depressed areas of southeastern Iberia, which reveal the places full of energy capable of generating centrality and development, preparing the territory for the arrival of global projects and reinforcing way continental reciprocal relationships with local identities.

Key words: hyperscale, crossroads, centrality, corridor 


\section{INTRODUCCIÓN}

El Sudeste lbérico es un territorio que merece un estudio razonado y apasionado del que puedan emerger nuevas estructuras de planificación que superen las carencias de las que existen, jerarquizadas, genéricas, ensimismadas e incapaces de abordar su complejidad y potenciar sus valores reales. Es un territorio sin rostro, sin plano, debido a las grandes distancias, a la múltiple división administrativa, a los agudos contrastes, a su escaso poblamiento... Esta región ha sido olvidada por su aislamiento, pero ahora es necesario dar respuesta al relevo estratégico de una obligada relación continental, un canal que enlazará Europa al litoral mediterráneo español, el llamado "corredor mediterráneo". Además, los desajustes que se presentan entre el marco legal de planeamiento y los problemas urbanísticos actuales, imposibilitan la adaptación de las identidades locales a estrategias de desarrollo y sostenibilidad global.

La investigación está orientada a la producción de una nueva forma de cartografiar el territorio, cuyas cualidades sean: enunciadoras, orientadoras, iluminadoras, inductoras, prospectivas, interpretativas, estratégicas,... Esta reforma está basada en la incorporación de nuevas herramientas y técnicas gráficas y comunicativas que promuevan la participación y difusión de un nuevo enfoque que haga útil el carácter atemporal de esta región. Se pretende aportar una forma de expresión y comunicación gráfica útil y extrapolable a otros territorios que enriquezca y genere urbanismo flexible y duradero. En la actualidad se echa en falta una metodología flexible, basada en estrategias y objetivos, que admita incorporaciones sucesivas que la enriquezcan y la refuercen en el tiempo, así como un método basado en la forma de observar los lugares clave y generadores del territorio actual y heredado, traducido en proyectos urbanos definidos con formas de representación cartográfica vivas e innovadoras, de carácter bidireccional, en el que realmente el plan genere proyecto y el proyecto reajuste el plan: Lo global se instala en lo local y a su vez lo global se constituye mediante una multiplicidad de ámbitos locales...

En este sentido, trabajos como los realizados por el Laboratorio de Urbanismo de Barcelona sobre la identidad del territorio catalán se utilizan como referente en el sentido de filtrado y selección de los elementos que se dibujan, ya que generan una serie de gráficos en los que se representa sólo lo valioso del territorio. Además, el ámbito comarcal en la que se desarrollan es otro de los elementos que resulta clave para el desarrollo de la investigación que se defiende en este trabajo.

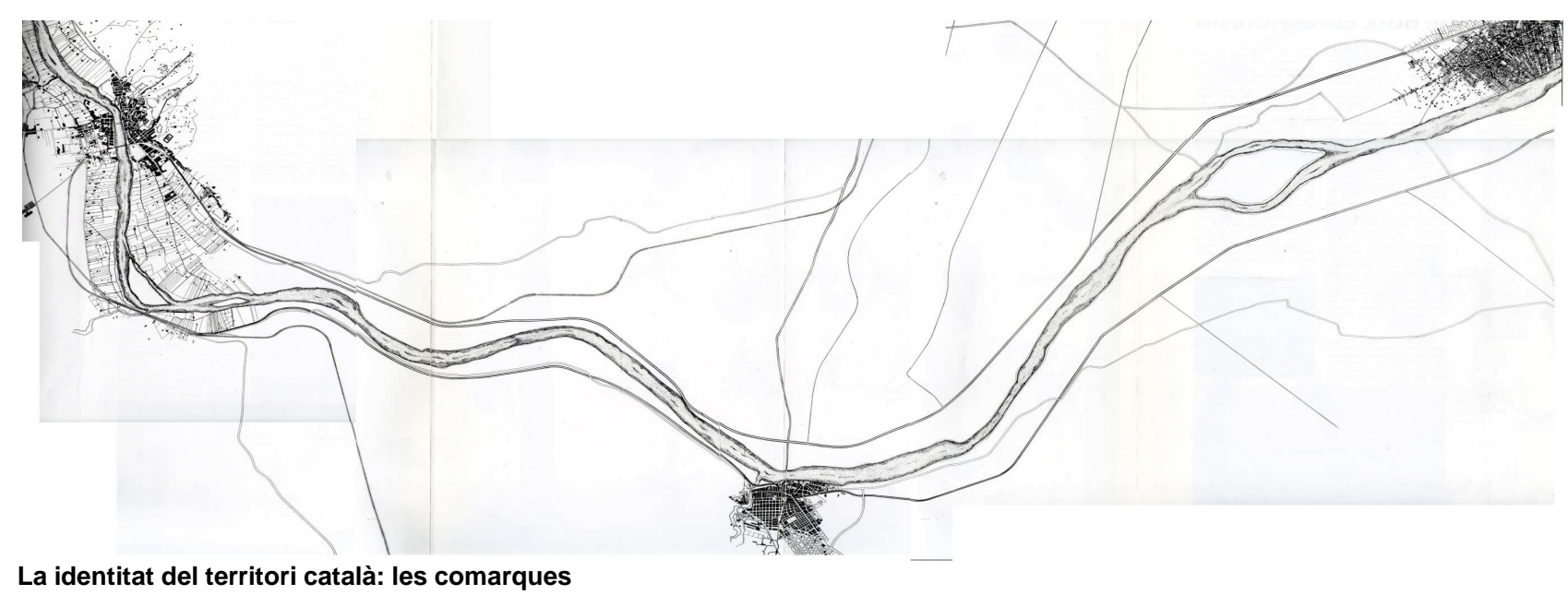

(Quaderns de Arquitectura y Urbanismo, 1981) 
Por otra parte la zona de estudio, respecto a la situación de las redes de comunicación ferroviaria en el país, forma parte de una de las grandes áreas desprovistas de este medio de movilidad, correspondiente al área de contacto entre las provincias de Granada, Almería, Murcia, Albacete y Ciudad Real.

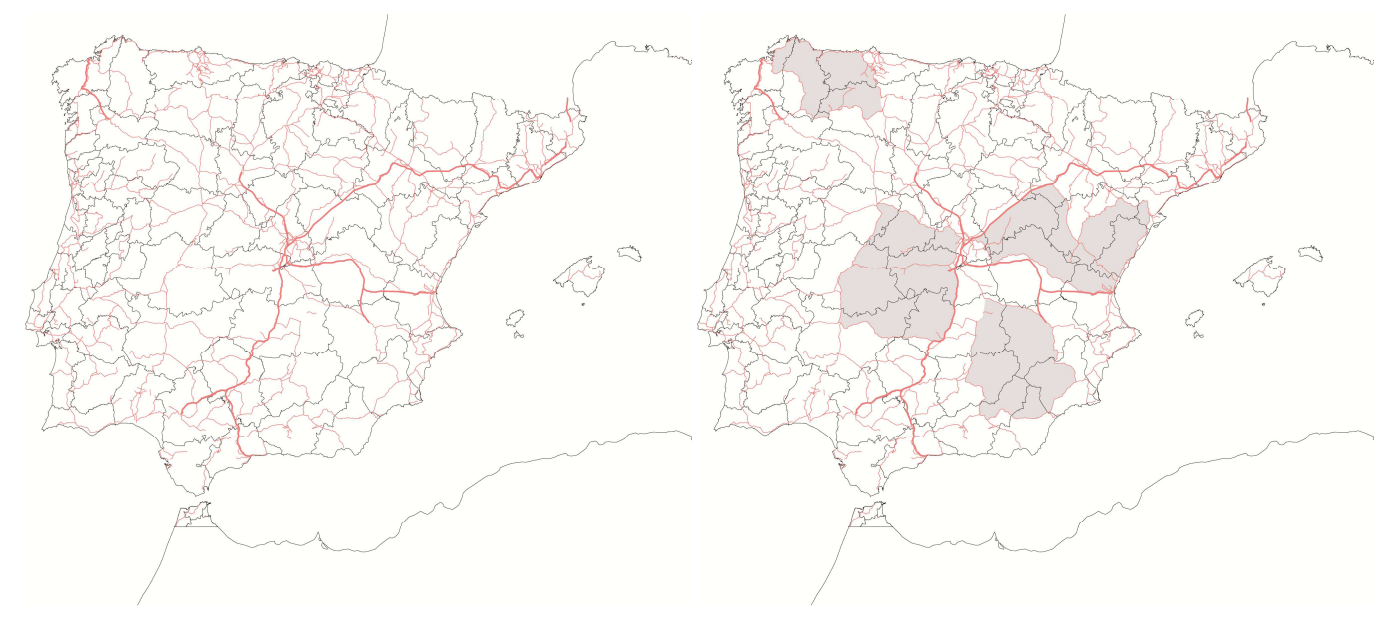

Si se observa el trazado del futuro corredor de alta velocidad, se puede comprobar que esa área vuelve a quedar desprovista de este medio.

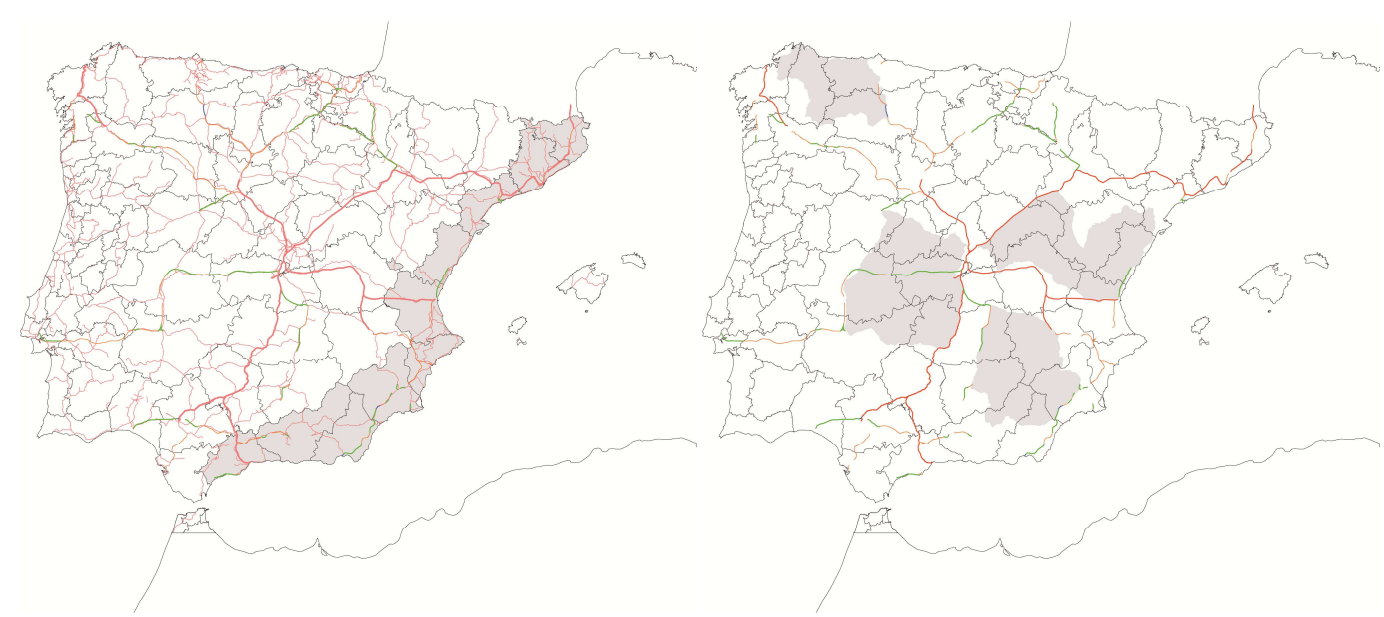

Red de transporte ferroviario actual y futuro

Elaboración propia a partir de planimetría del IGN

Se atenderá especialmente a la repercusión, tanto económica y social como física, que tendrá el corredor ferroviario sobre la región sudeste y a la generación, en consecuencia, de directrices que orienten sobre cómo ordenar el territorio, no sólo para la llegada de esta nueva infraestructura de relación global sino, además, para las respuestas que puedan producirse en lugares más concretos. Estos territorios se encuentran ante el reto de inventar operaciones de nivel local que deben coexistir y responder a operaciones de nivel global.

Son esos proyectos los encargados de dar forma a la cadena de eslabones locales que dará o no continuidad a las estrategias de mayor escala en su irrigación del territorio más cercano. Estos espacios son entendidos en este trabajo como lugares geográficos con identidades e inquietudes particulares no dependientes de ningún límite geográfico o administrativo.

Se utiliza en la investigación el concepto de "puertas territoriales", entendido como el paso entre los elementos de intersección y unión entre estos "eslabones de identidad local". Éste debe ser objeto de una atención particular ya que de esos lugares clave de encrucijada y centralidad territorial y de su correcta soldadura depende la generación de territorio, así como de nuevas economías, proyectos y relaciones. El hábitat y la historia de este territorio es latente y visible, y ello hace que sea necesario rescatar y profundizar, mediante la generación de cartografía específica, actual, diagramática, física y propositiva, características topográficas, geográficas, económicas, sociales, agrícolas, hidrológicas, paisajísticas... 
Relacionado con lo anterior, el hallazgo e invento o re-invento de nuevos y viejos lugares que entren en este rol escalar, pasa por perseguir los siguientes objetivos:

- Cartografiar los lugares aportando una nueva forma de comunicación gráfica de los territorios, sea cual sea su ámbito.

- Desvelar a través del dibujo los grandes rasgos singulares e identitarios de los distintos ámbitos de estudio.

- Construir una descripción de estos rasgos para hacer entendible el territorio a través de una cartografía de elaboración sintética y direccionada.

- Producir, utilizando los distintos sistemas de representación, una serie cartográfica descriptiva y a partir de ella obtener una proyectual.

\section{MATERIAL Y MÉTODOS}

Esta reflexión pretende demostrar que los territorios, en su "punto de partida", poseen intrínsecamente los elementos clave (materiales, agua, clima, trazas, direcciones, historia, hábitats, sociedades, economías, caminos, topografía, vegetación, agriculturas,...) capaces de desvelar "el proceso inicial" de sus líneas futuras de desarrollo, así como que, para cada ámbito de estudio, el encuadre y las escalas de visión y de representación son variables, pero que existe un par clave que define de forma completa el lugar así como las grandes oportunidades estratégicas que puede acoger.

La metodología empleada para tal fin utiliza tanto un método como unos materiales singulares para este trabajo en particular. Aunque los tres primeros episodios que se utilizan en la metodología podrían considerarse clásicos, su conjunción y unión con los dos siguientes hacen que la forma de enfrentarse al territorio no sea común. Se desarrolla la siguiente forma de trabajo:

- Caracterización y justificación de la elección del área de estudio. Localización de encrucijadas territoriales.

- Descripción y observación de la encrucijada elegida para su estudio.

- Encuadres elegidos para encrucijada y definición del concepto ámbito hiperescalar.

- Codificación y caracterización de los distintos sub-ámbitos hiperescalares.

- Generación de nuevas cartografías.

A través de este método se persigue avanzar en la idea de que "la sociedad es la idealización de aquello que ocurre en el territorio" (Dematteis, 2006:4).

\subsection{Caracterización y justificación de la elección del área de estudio: Localización de encrucijadas territoriales}

El territorio en el cual se desarrolla la investigación atiende a las provincias de Granada, Almería, Murcia y Jaén ya que su posición, dentro del panorama nacional y europeo, constituye una oportunidad estratégica con la implantación de la línea de alta velocidad ferroviaria planteada como "Corredor Mediterráneo", y que unirá España con Europa.

Concretamente el trabajo se centra en el Altiplano granadino y las Hoyas de Guadix y Baza, que conforman una de las plataformas y de los valles por los que discurre el "Corredor Natural Intrabético" uniendo los valles de Guadalquivir y Segura y cohesionando las provincias orientales andaluzas con levante.

Son cuatro elementos geográficos los que dan paso al altiplano y seguidamente a la depresión: Puerto Lumbreras (E), Puerto de la Mora (O), Campo de Tabernas (SE) y el Guadiana Menor (NO). Todo este marco geográfico constituye una fuerte encrucijada territorial que históricamente ha supuesto un lugar de paso bajo la imponente presencia e influencia del techo ibérico de Sierra Nevada. Esta planicie y depresión constituyen un cuádruple soporte de comunicación entre:

A. El Levante hacia el Este, tras cruzar Puerto Lumbreras y Lorca para llegar a las fértiles huertas de Murcia y Valencia, mercado hortofrutícola de Europa y a sus litorales donde el turismo de sol y playa encuentra uno de sus mayores referentes. 
B. La Vega de Granada y valle del río Genil hacia el Oeste, cruzando el Puerto de la Mora y desde aquí hacia el Sur la relación con la Costa Tropical tras flanquear el Puerto del Suspiro del Moro acompañando al Río Guadalfeo en su descenso al mar entre la Alpujarra y la Contraviesa.

C. El Litoral de Almería, hacia el Sureste, circundando la Sierra de Baza, bien por el Valle del Zalabí y atravesando el Campo de tabernas o bien por la ruta del Mármol para llegar en ambos casos al Parque Natural del Cabo de Gata-Níjar.

D. La Sierra de Cazorla y cabecera del Río Guadalquivir, hacia el Noroeste, con Úbeda y Baeza como antesala de la desembocadura del río Guadiana Menor en el Río Guadalquivir.

Los plegamientos originaron grandes conjuntos orográficos y morfotectónicos: La Cordillera Penibética que bordea la costa y donde se hallan las culminaciones del sistema: Ronda 1919 m; Almijara 1824 m; Tejeda 2065 m; Nevada 3478 m; Baza 2269 m; Gádor 2522 m; Filabres 2168 m; Estancia 1718 m.; y la Cordillera Subbética alineada paralelamente al norte de la primera: Grazalema 1654 m; Pandera $1601 \mathrm{~m}$; Mágina 2167 m; Harana 1931 m; Segura 1830 m; Sagra 2381 m; Espuña 1579 m.

Entre ambas unidades serranas se intercala una amplia depresión longitudinal fuertemente estrangulada, pero con suficiente personalidad para separar los relieves de los dos grandes conjuntos orográficos y tectónicos. Se trata de la Depresión Intrabética o Penibética formada por el Corredor de Boyar, Hoyas de Antequera, Granada, Guadix y Baza..." (M. de Teran, I. Solé Sabarís y otros, 1978)

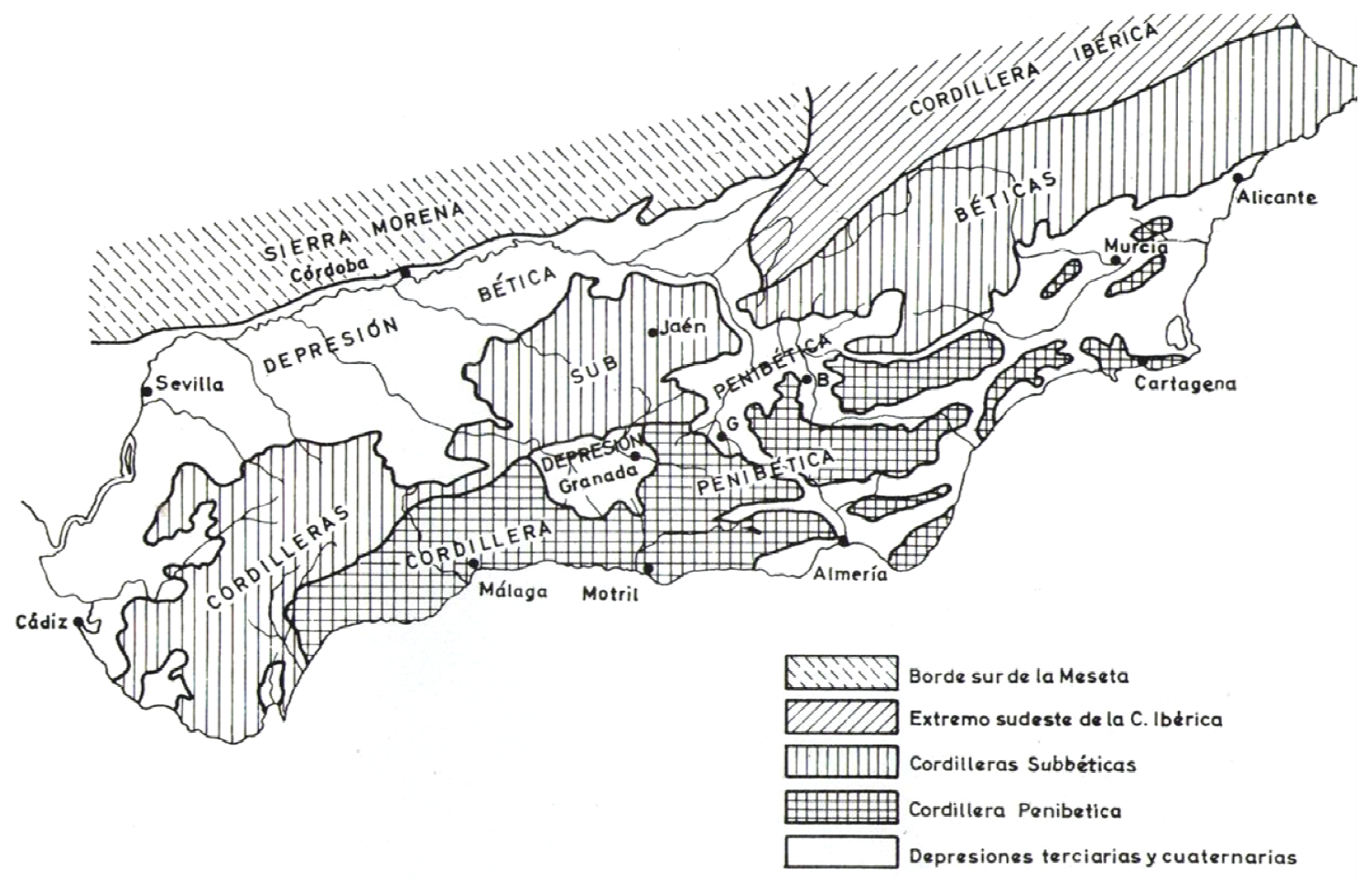

Unidades morfoestructurales de Andalucía

(Solé Sabarís, 1978)

Esta encrucijada espacial y de comunicación forma parte de una constelación de centralidades territoriales que dan coherencia y frecuencia a estas regiones. Del entrelazamiento entre ellas depende la consistencia de la malla territorial y, asociados a la red que se genera, los sistemas económicos y sociales del territorio. 


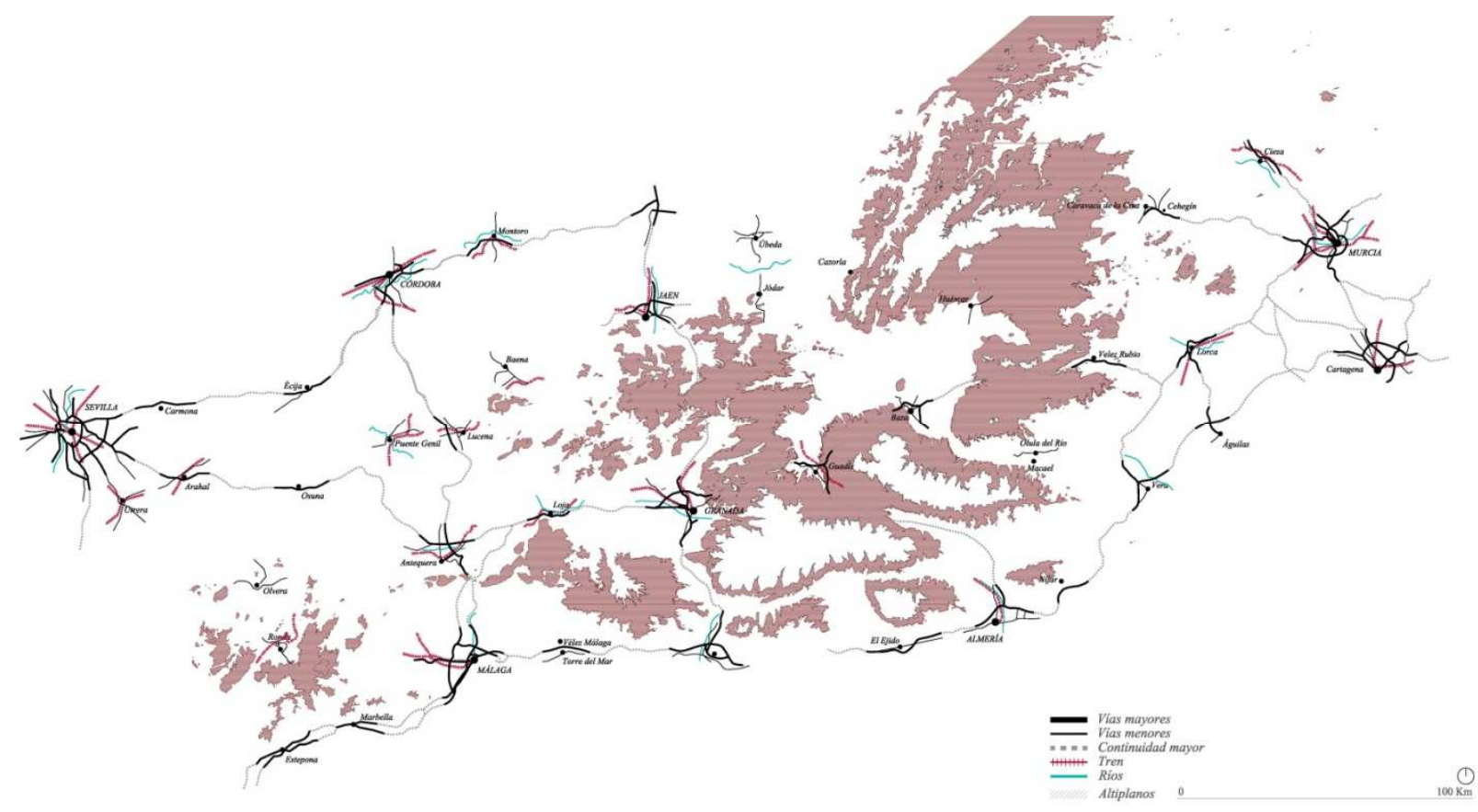

Grandes y medias encrucijadas territoriales de Andalucía

Elaboración propia a partir de cartografía de la Junta de Andalucía

El trabajo de investigación se desarrolla dentro del ámbito mencionado del Altiplano granadino y las Hoyas de Guadix - Baza y centra su atención en desarrollar cartográficamente la encrucijada formada por los itinerarios entre Úbeda - Vera y Granada - Lorca. Esta escala comarcal es la que proporciona, en este tipo de territorios, más información relevante. La fuerte centralidad de las ciudades medias, Guadix y Baza, posibilita la permanencia de sistemas de comunicación intermunicipal, saberes populares heredados de árabes y romanos, sistemas tradicionales de regadío y trashumancia... así como la conciencia periférica y dispersa respecto a las ciudades capitales, provinciales, regionales o estatales, que hacen de estas regiones menores reductos que luchan por la supervivencia y el progreso.

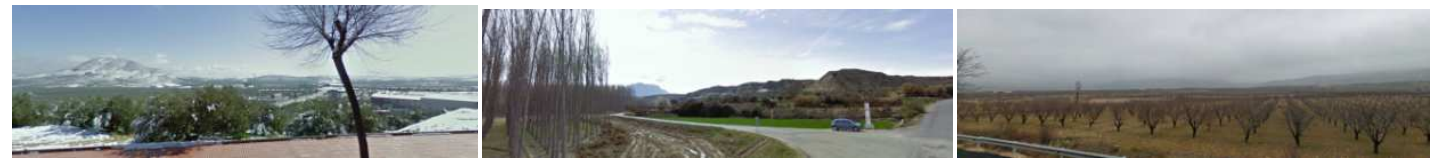

\subsection{Descripción y observación de la encrucijada elegida para su estudio}

Diferentes épocas y economías han apostado por esta región y por sus recursos, pero no han conseguido sostenerse en el tiempo. Así las explotaciones mineras, promovidas en el pasado por culturas inglesas y centroeuropeas como las de Alquife, la Unión, Linares, Mazarrón, Marquesado..., están prácticamente extintas y soportando estrategias efímeras de turismo. Sin embargo, la agricultura y la ganadería, sobre todo la primera, han sido capaces de evolucionar y adaptarse, siendo el principal medio de supervivencia y mantenimiento de este territorio, en el que hoy surgen instalaciones de producción de energías renovables.

Dejando al margen la playa, el sol y la nieve, el turismo en esta zona es básicamente rural, débil y agarrado a sus valores seguros: las viviendas cueva, el desierto, la montaña, los vergeles y oasis de la hoya, el patrimonio histórico... La energía del lugar está latente y presente en su paisaje y geografía. Es una región compuesta y heterogénea, un mosaico policromado castigado por el sol y formado por grandes extensiones áridas, salpicadas de vergeles distribuidos en sus hoyas y mesetas. Estos paisajes constituyen para Europa un lugar de fuerte personalidad. Cabe apreciar la diversidad de sus ecosistemas; la fuerte presencia de los sistemas Béticos asociados a grandes espacios naturales protegidos; las bajadas a los valles de formación característica denominada badlands; la alta presencia de fuentes y manantiales; la horizontalidad del altiplano con telón de fondo las cumbres de la sierra; los pueblos blanqueados estampados en las montañas; los llanos de cereales, almendros y olivares; los oasis de choperas, huertos, melocotones y frutales; las agriculturas tradicionales en terrazas; los peñascos blancos de calizas; los embalses y pantanos; la oxidada arquitectura minera; las pitas, las chumberas, el esparto y las retamas... 

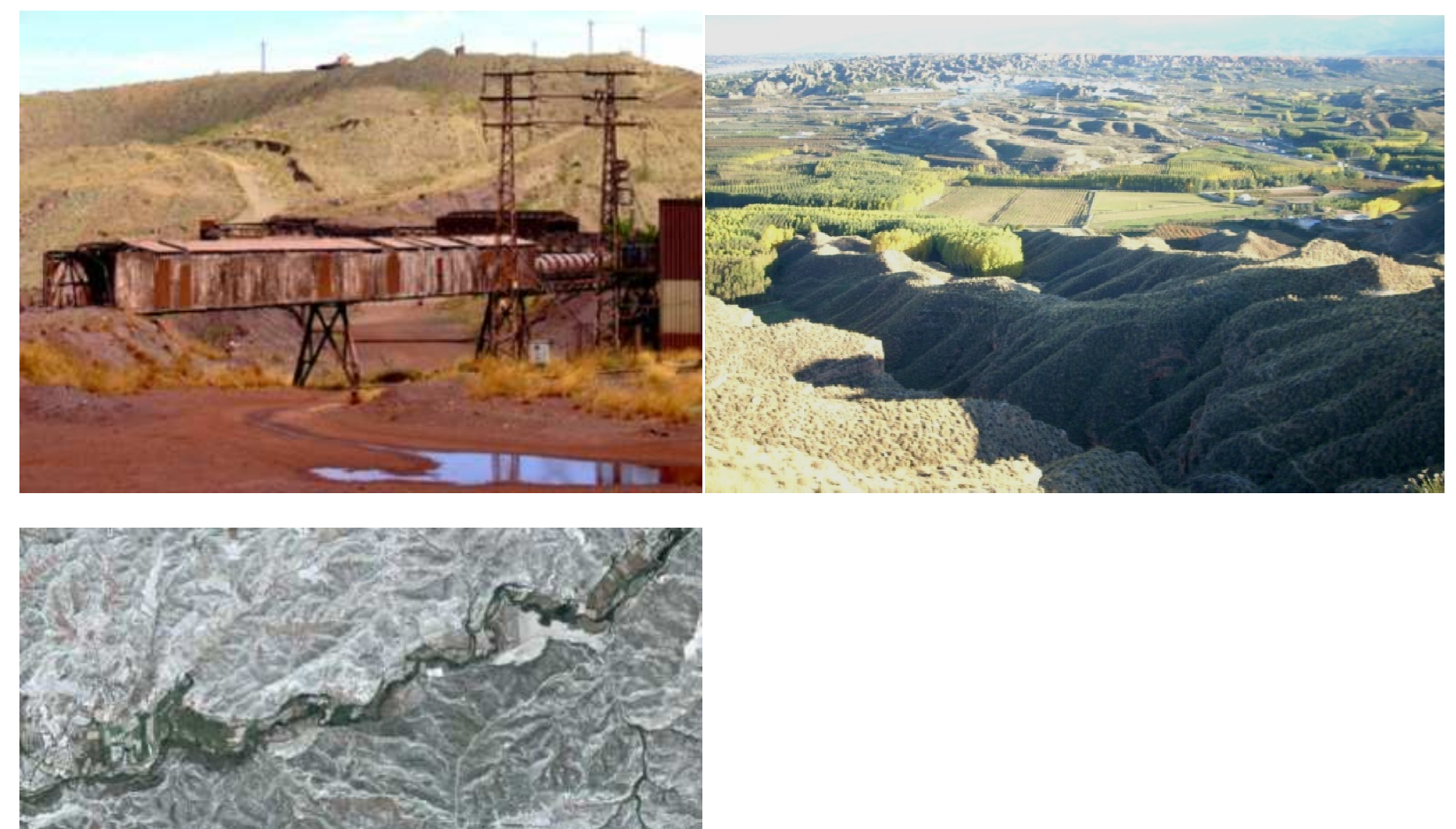

Fotografías de las minas de Alquife, los Badlands y ortofofografía de la Hoya de Guadix Elaboración propia

La actualidad y la forma de asumir el cambio de perspectiva energética han provocado un cambio en la imagen de este paisaje. Los grandes e imponentes campos del Marquesado han sustituido el trigo y la cebada por espigados molinos de viento de empresas europeas o por grandes extensiones de acumulación de energía solar que se mecen con el recorrido del astro de este a oeste. Igualmente el paisaje ha sufrido una profunda transformación en otros puntos del altiplano, como en la bajada a Almería por Fiñana o la llegada a Lorca.

\subsection{Encuadres elegidos para encrucijada y definición del concepto ámbito hiperescalar.}

La localización de la encrucijada elegida se encuentra en un espacio intermedio de tamaño comarcal que depende de dos encuadres mayores y que encierra dos más menores. En total son cinco los encuadres de estudio escogidos de manera intencionada y seleccionados para su desarrollo en este trabajo.

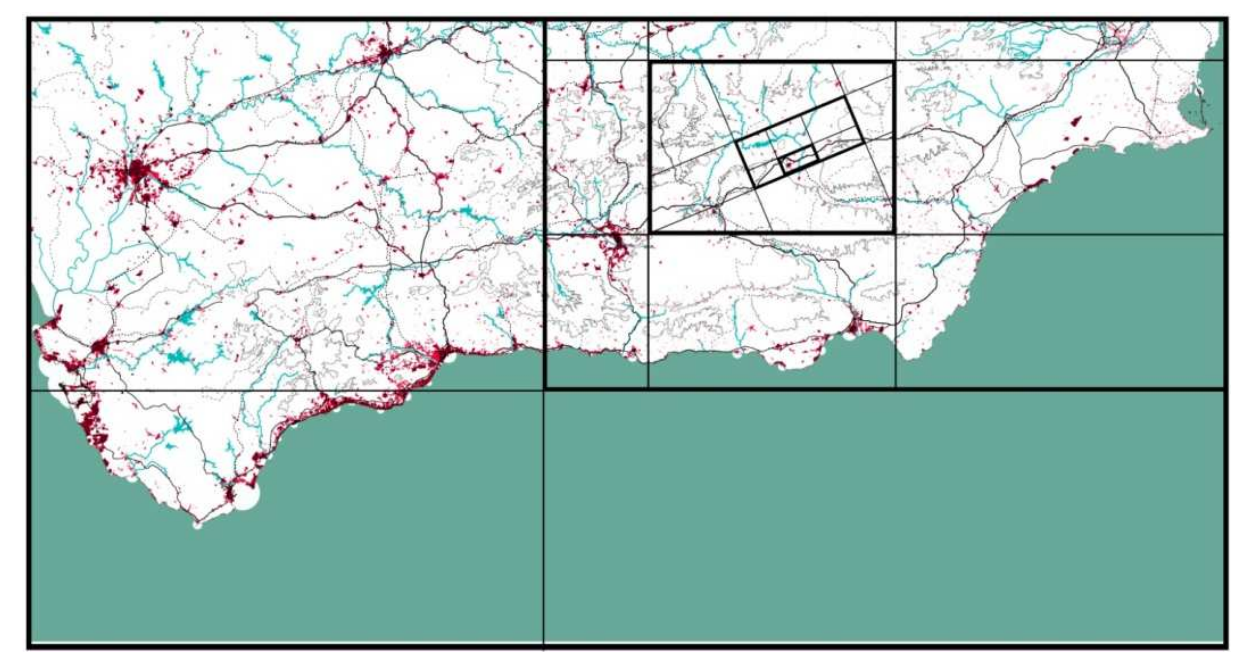

Para denominar la forma de mirar estos encuadres se ha utilizado el concepto "hiperescala", con el fin de hacer patente que "la mirada urbana del territorio es capaz de establecer múltiples relaciones interescalares aunque se observe a una determinada escala", (Rivas, 2001). 
Un ámbito territorial está compuesto a su vez por sub-ámbitos menores. Estas partes territoriales son detectadas y clasificadas en función de sus diversos parámetros cuantitativos y cualitativos: posición, clima, usos, morfología, agua, antigüedad, orientación... A continuación se expresan gráficamente los sub-ámbitos detectados para cada una de las hiperescalas. Se comprende así que las cualidades de un territorio pertenezcan a su vez a múltiples de ellos en función de la distancia con la que se observa.

Hiperescala A. La escala regional.

Hiperescala B. La escala del paisaje.

Hiperescala C. La escala comarcal.

Hiperescala D. La escala local.

Hiperescala E. La escala del hábitat.

Una vez diferenciadas estas subdivisiones, cada una de estas hiperescalas se desarrolla en el trabajo de manera transversal con las anteriores y posteriores. La transversalidad de este método radica en la forma de representarlos. Para cartografiar las cinco escalas se ha optado por ensayar el mismo criterio gráfico para todas, por lo que la representación de los lugares se traduce en conceptos que se verán más adelante.

\subsection{Codificación y caracterización de los distintos sub-ámbitos hiperescalares.}

Cada ámbito hiperescalar se encuentra compuesto por multitud de sub-ámbitos. Para su desarrollo no se tienen en cuenta los límites administrativos como límites reales sino que se consideran las características geomorfológicas, ambientales y sociales para definir los espacios reales que supone cada uno de los lugares. Con este procedimiento se han establecido grupos para las distintas escalas de estudio.

Paola Viganò, demuestra en su trabajo sobre la città elementare, cómo los territorios pueden ser observados y analizados como compuestos de patrones o elementos menores, físicos o sensoriales, que son los que propiamente han dado forma y sentido a los lugares.

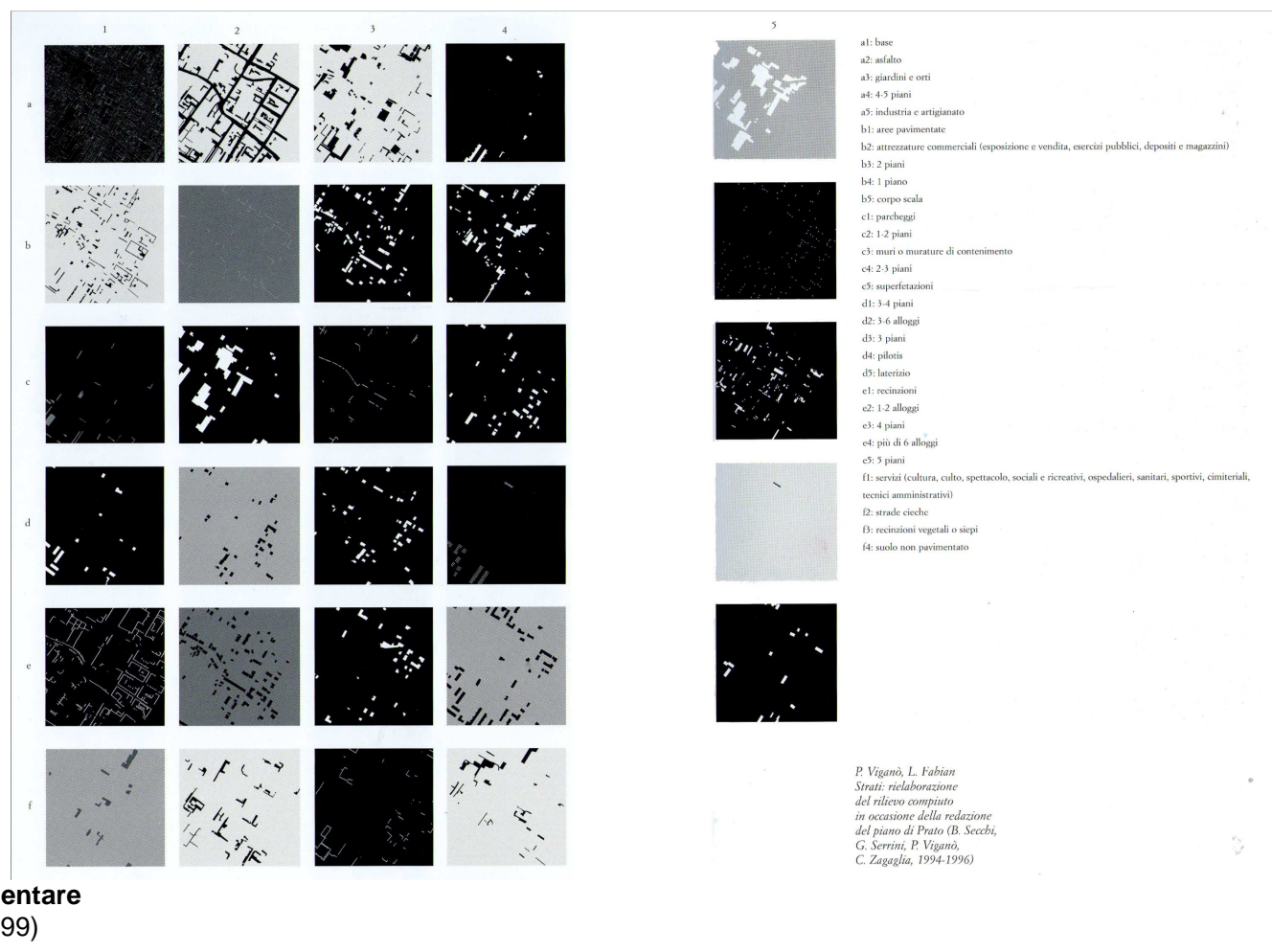

La città elementare

(Vigano,P. 1999)

En las siguientes tablas, estos ámbitos menores se codifican, se identifican y se caracterizan en función de patrones fundamentales presentes en el territorio, como son: Materia, Escala, Tiempo, Clima, Orientación, Tipología edificatoria, Orografía, Agua, Historia, Economía, Color, Patrimonio, Cultura...

De este modo, cada hiperescala menor acumula las características de la mayor, lo que proporciona gran cantidad de información para los proyectos que se pudieran llevar a cabo en los distintos lugares. 


\subsubsection{Hiperescala A. La escala regional. (Sub-ámbito territorial A. El Sudeste Ibérico)}

Codificación e identificación

\begin{tabular}{l|l} 
A1 & Depresión del Guadalquivir \\
\hline A2 & Cordilleras béticas \\
\hline A3 & Levante español \\
\hline
\end{tabular}

Caracterización del Sub-ámbito

\begin{tabular}{|l|l|}
\hline \multirow{A}{*}{2} & $\begin{array}{l}\text { Zona montañosa } \\
\text { Agricultura tradicional } \\
\text { Escasez de agua } \\
\text { Climatología dura... }\end{array}$ \\
\hline
\end{tabular}

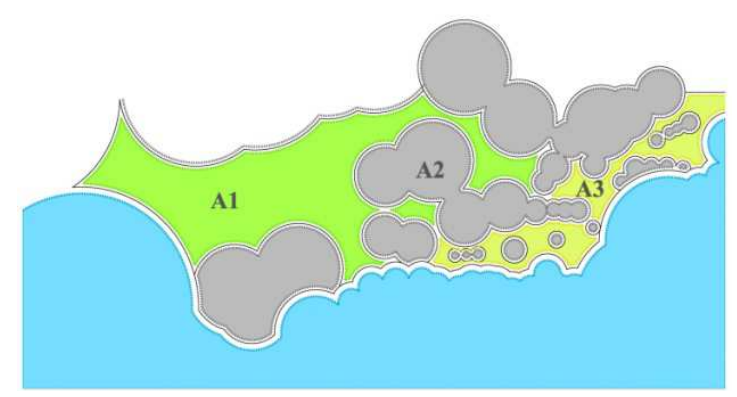

\subsubsection{Hiperescala B. La escala del paisaje. (Sub-ámbito territorial A2. Las Cordilleras Béticas)}

Codificación e identificación

\begin{tabular}{l|l} 
B1 & Cabecera del R. Guadalquivir \\
\hline B2 & S. Cazorla, Segura y las Villas \\
\hline B3 & Comarca de los Vélez \\
\hline B4 & Altiplanos granadinos \\
\hline B5 & Hoyas de Guadix-Baza \\
\hline B6 & Sierra de Baza \\
\hline B7 & Sierra Nevada \\
\hline B8 & Vega de Granada \\
\hline B9 & Comarca del mármol \\
\hline B10 & Cavo de Gata \\
\hline B11 & Desierto de Tabernas \\
\hline B12 & Campos de Nijar \\
\hline B13 & Campo de Dalías \\
\hline B14 & Vega de Lorca \\
\hline B15 & Playas de Vera \\
\hline B16 & Mazarrón \\
\hline B17 & Campo de Cartagena \\
\hline B18 & Huerta de Murcia \\
\hline B19 & Sierra de Murcia \\
\hline B20 & Costa tropical \\
\hline B21 & S. Tejeda y Almijara \\
\hline B22 & S. Mágina
\end{tabular}

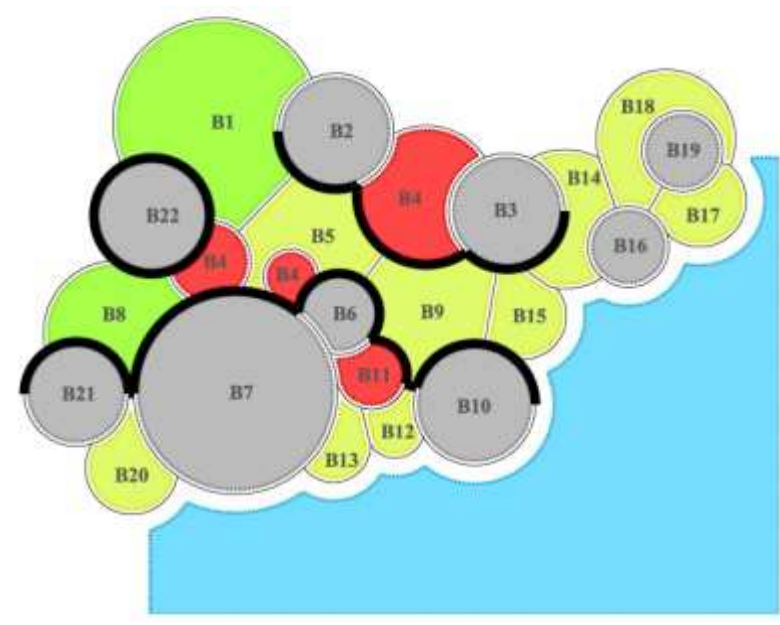

Caracterización del Sub-ámbito

\begin{tabular}{|l|l|l|l|l|l|}
\hline & Zona montañosa & Escasez de agua & Subdesértico & Cuevas & Depresión \\
B5 & Agricultura tradicional & Climatología dura & Bajo cota 1000 & Vergeles & Nacimientos... \\
\hline
\end{tabular}

\subsubsection{Hiperescala C. La escala comarcal. (Sub-ámbito territorial B5. Las Hoyas de Guadix-Baza)}

Codificación e identificación

\begin{tabular}{l|l} 
C1 & Hoya de Guadix \\
\hline C2 & E. Negratín - cerro jabalcón \\
\hline C3 & Hoya de baza \\
\hline C4 & Cornisa noreste \\
\hline C5 & Aliviadero del Guadiana menor \\
\hline C6 & Cerros de Úbeda
\end{tabular}

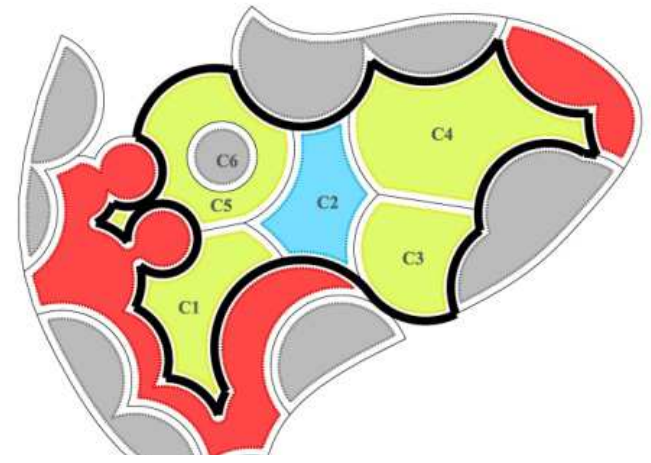

Caracterización del Sub-ámbito

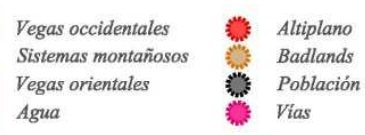

\begin{tabular}{|c|c|c|c|c|c|}
\hline C2-C3 & $\begin{array}{l}\text { Zona montañosa } \\
\text { Agricultura tradicional } \\
\text { Escasez de agua } \\
\text { Climatología dura }\end{array}$ & $\begin{array}{l}\text { Subdesértico } \\
\text { Bajo cota } 1000 \\
\text { Cuevas } \\
\text { Vergeles }\end{array}$ & $\begin{array}{l}\text { Depresión } \\
\text { Nacimientos } \\
\text { Ramblas }\end{array}$ & $\begin{array}{l}\text { Ríos } \\
\text { Badlans } \\
\text { Hito visual }\end{array}$ & $\begin{array}{l}\text { Antiguo lago } \\
\text { Prehistoria } \\
\text { Huertas } \\
\text {... }\end{array}$ \\
\hline
\end{tabular}




\subsubsection{Hiperescala D. La escala local. (Sub-ámbito territorial C2, C3 y C4. Pantano del Negratín- Jabalcón, Hoya de Baza Sur y Hoya de Baza Norte)}

Codificación e identificación

\begin{tabular}{l|l} 
D1 & Baza \\
\hline D2 & Jabalcón \\
\hline D3 & Vega de baza \\
\hline D4 & Embalse del Negratín \\
\hline D5 & Triada Zújar-Freila-Bácor \\
\hline D6 & Badlans del sur \\
\hline D7 & Benamaurel \\
\hline D8 & Badlans del este \\
\hline D9 & El margen-la alquería \\
\hline D10 & Cúllar-venta del peral \\
\hline D11 & Río Cúllar \\
\hline D12 & Badlands del sureste \\
\hline D13 & Paso de Caniles \\
\hline D14 & Caniles
\end{tabular}

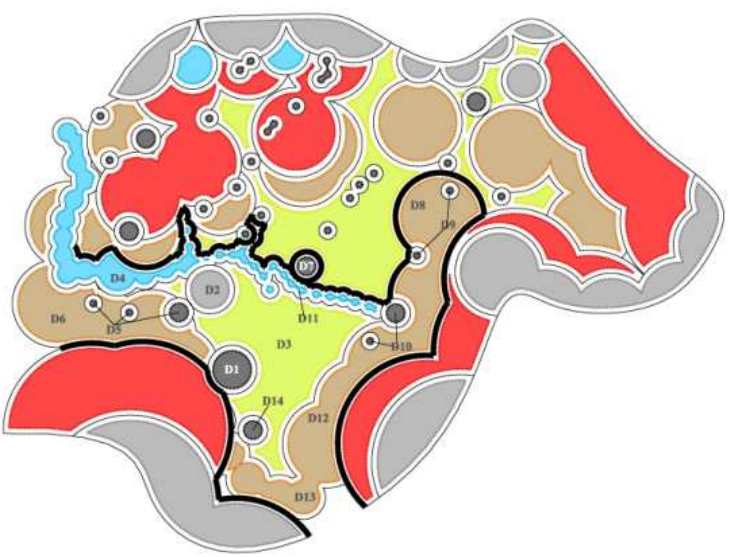

Caracterización del Sub-ámbito

\begin{tabular}{|l|l|l|l|l|l|}
\hline & Zona montañosa & Vergeles & Huertas & Directriz murcia & Zona industrial \\
& Agricultura tradicional & Depresión & Ramblas & Musulmana & Hospital \\
& Escasez de agua & Nacimientos & Ríos & Ciudad dispersa & Cascamorras \\
D1 y D3 & Climatología dura & Badlans & Romana & Carretera nacional & Altiplano... \\
& Subdesértico & Hito visual & Ciudad media & Alcazaba & \\
& Bajo cota 1000 & Antiguo lago & Ladera & Antigua estación y & \\
& Cuevas & Prehistoria & Orientación este & línea de ff.cc & \\
\hline
\end{tabular}

\subsubsection{Hiperescala E. La escala del hábitat. (Sub-ámbito territorial D1 y D3. Baza y Vega de Baza)}

Codificación e identificación

\begin{tabular}{l|l} 
E1 & Baza \\
\hline E2 & Rambla Rodadas y Seguidillas \\
\hline E3 & Vega sur de Baza \\
\hline E4 & Carretera de Caniles y traza del ferrocarril \\
\hline E5 & Río Baza \\
\hline E6 & Vega este de Baza \\
\hline E7 & Carretera de Murcia \\
\hline E8 & Albarrá \\
\hline E9 & Acequia Ojillo de la Muela \\
\hline E10 & Balsa Nueva \\
\hline E11 & A92 Norte \\
\hline E12 & A92 Este \\
\hline E14 & Hospital \\
\hline E15 & Polígono \\
\hline E16 & A7301 \\
\hline E17 & A334 y antigua traza del ferrocarril \\
\hline E18 & Las Casas de Muñoz \\
\hline E19 & A334 noroeste \\
\hline E20 & A334 norte y cementerio \\
\hline E21 & M92 noroeste \\
\hline
\end{tabular}

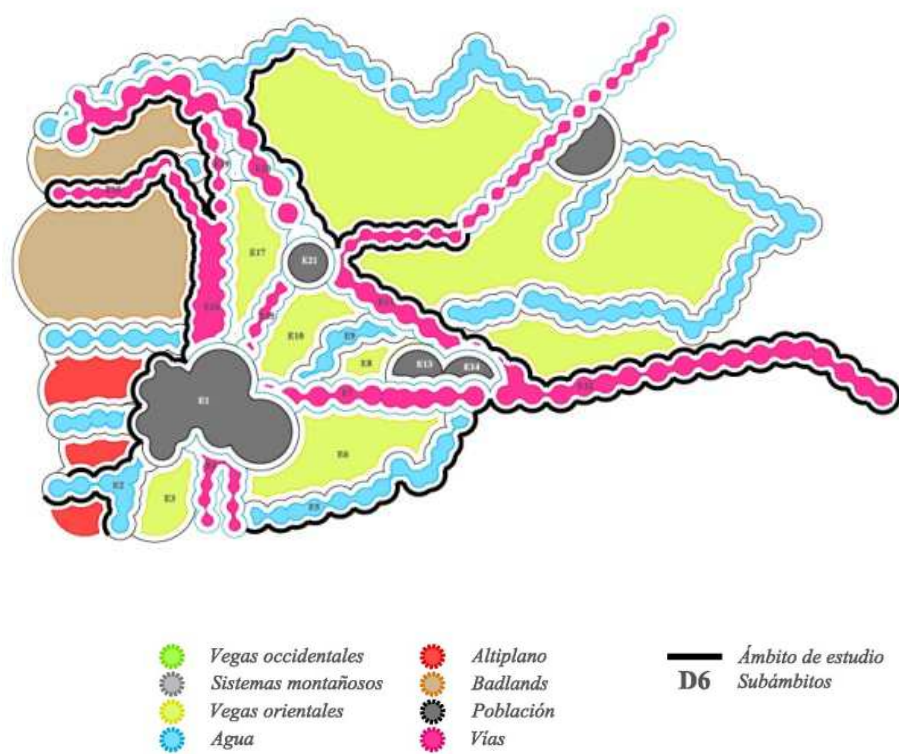

Caracterización del Sub-ámbito

\begin{tabular}{|l|l|l|l|l|l|}
\hline & Zona montañosa & Depresión & Ríos & Carretera nacional & Almazaras \\
& Agricultura tradicional & Nacimientos & Romana & Alcazaba & Acequias \\
E1, E4, & Escasez de agua & Badlans & Ciudad media & Antigua estación y línea de ff.cc & A92 \\
E7, E13, & Subdeséría dura & Hito visual & Ladera & Zona industrial & Saminos \\
E14, E15 & Bajo cota 1000 & Antiguo lago & Orientación este & Hospital & Ruta de Baza \\
y E16 & Cuevas & Prehistoria & Directriz Murcia & Cascamorras & Rármol \\
& Vergeles & Huertas & Musulmana & Altiplano & Tradiciones \\
\hline
\end{tabular}




\subsection{Generación de nuevas cartografías}

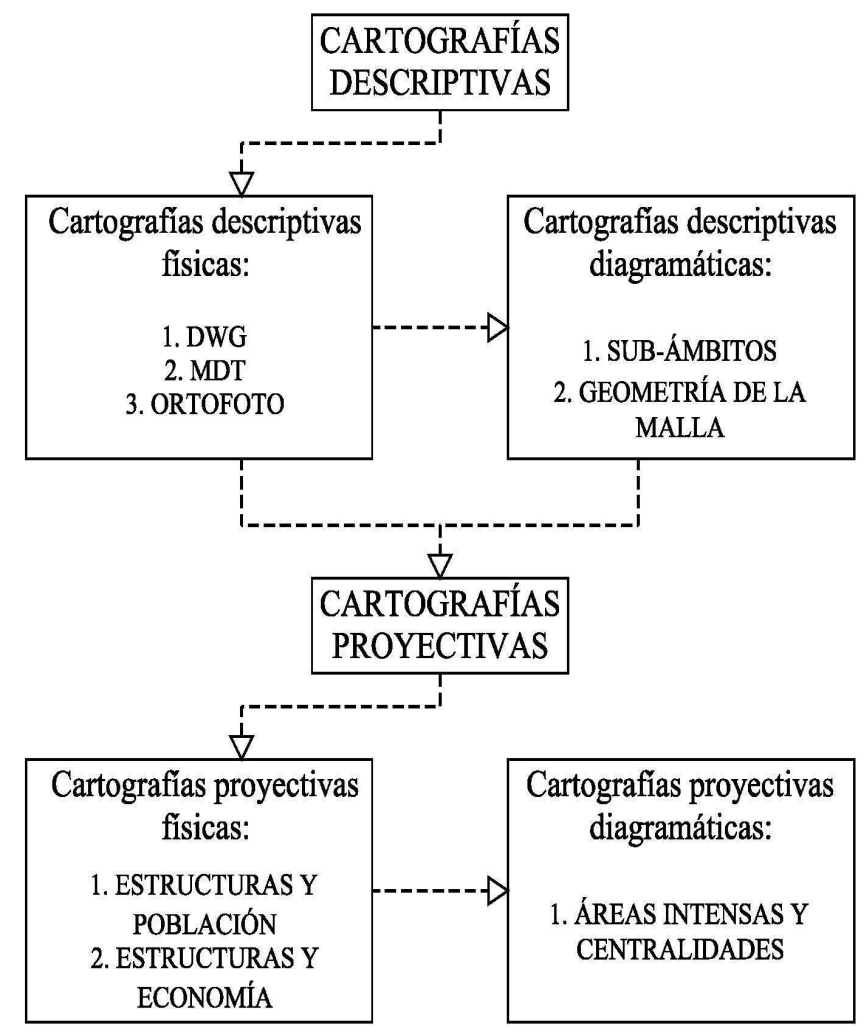

Diagrama metodológico empleado para la generación de nuevas cartografías

Elaboración propia

Tras todo lo anterior, este punto desarrolla nuevas cartografías, teniendo en cuenta toda la información obtenida, tanto cuantitativa como cualitativa, sobre las cinco hiperescalas definidas que engloban las encrucijadas interesantes del territorio entorno al corredor intrabético que une el levante de la península ibérica con el valle del Guadalquivir. Básicamente de trata de generar cartografías que preparen el territorio para la llegada de nuevos proyectos y energías.

Se producen dos tipos de cartografías; unas descriptivas y de un tono más estático y analítico que servirán de base para la generación de un segundo tipo, proyectivo, de carácter inductor y direccionado a la obtención de material útil para la ordenación territorial. Además, para la generación de estos recursos gráficos se utiliza un mismo criterio de representación para todas las escalas y encuadres, con el fin de demostrar la flexibilidad del dibujo a la hora de enfrentarse a un soporte gráfico. Tanto las cartografías descriptivas como las proyectivas se dividen a su vez en dos categorías, utilizando de nuevo la primera como instrumento más descriptivo y como soporte base para la generación de la segunda: 
Cartografías Descriptivas:

- Producción de una Cartografía Descriptiva Física, (C.D.Fis.): Se utilizan sistemas cartográficos digitales, fotografía aérea, material obtenido en el trabajo de campo, bibliografía, ... que constituye la primera base material.

- Extracción de una Cartografía Descriptiva Diagramática (C.D.Diag.): Sintetiza la información producida en el apartado anterior.

Cartografías Proyectivas:

- Producción de una Cartografía Proyectiva Física (C.P.Fis.): Selecciona lo relevante de la información y diagramatiza las cartografías descriptivas.

- Producción de una Cartografía Proyectiva Diagramática (C.P.Diag.): Identifica los lugares de intensidad, posibles nuevas centralidades y de oportunidad. Genera un nuevo plano de base proyectual. 


\section{은}

Hiperescala A. La escala regional

○

Hiperescala B. La escala del paisaje

\section{O}

Hiperescala C. La escala comarcal

\section{0}

Hiperescala D. La escala local

\section{0}

Hiperescala E. La escala humana Cartografía descriptiva física. DWG

Elaboración propia a partir de cartografía de la Junta de Andalucía

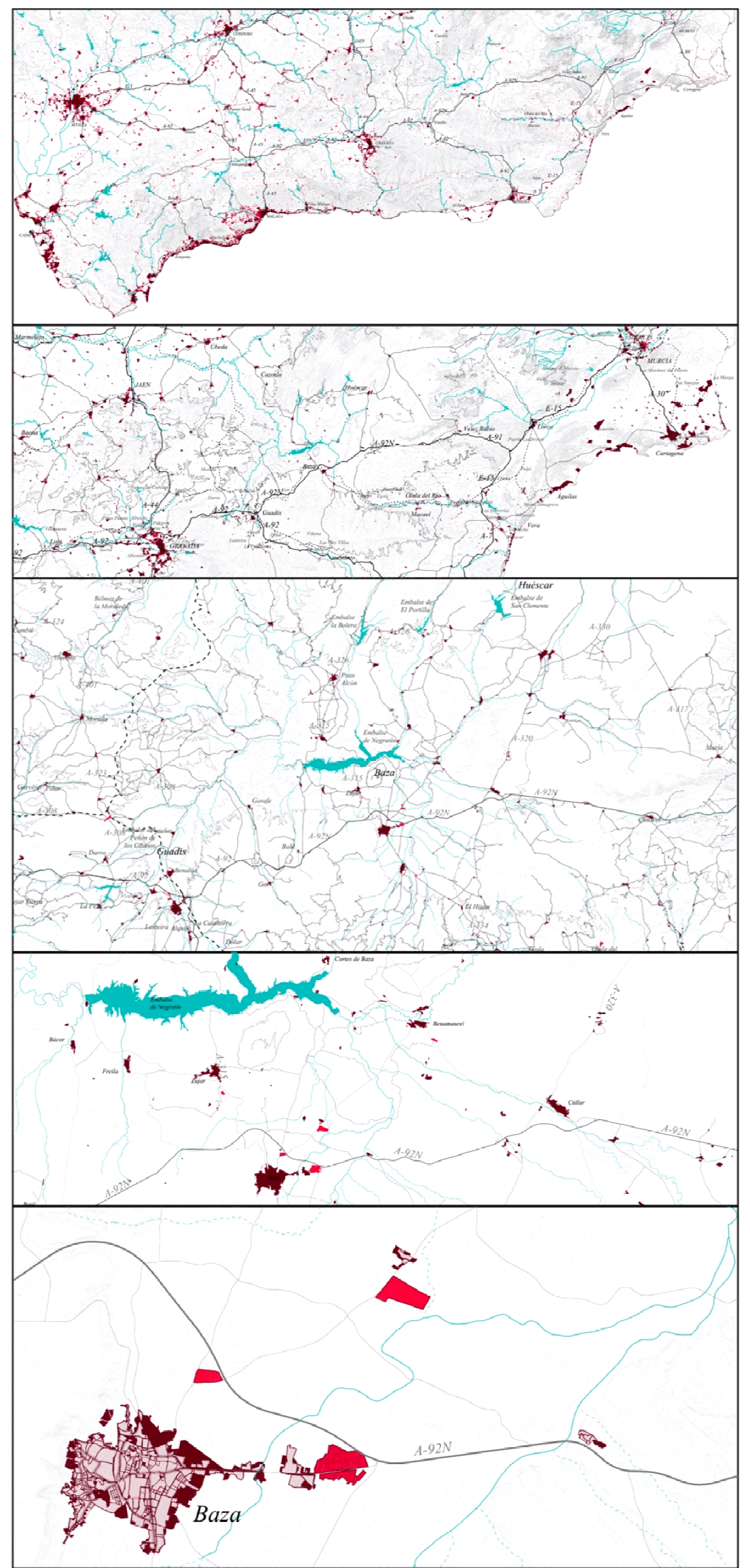


2.5.2 Cartografía descriptiva física ORTOFOTOGRAFÍA

으

Hiperescala A. La escala regional

○

Hiperescala B. La escala del paisaje

0

Hiperescala C. La escala comarcal

0

Hiperescala D. La escala local

0

Hiperescala E. La escala humana

Cartografía descriptiva física. ORTOFOTOGRAFIA

Elaboración propia a partir de visor de IBERPIX
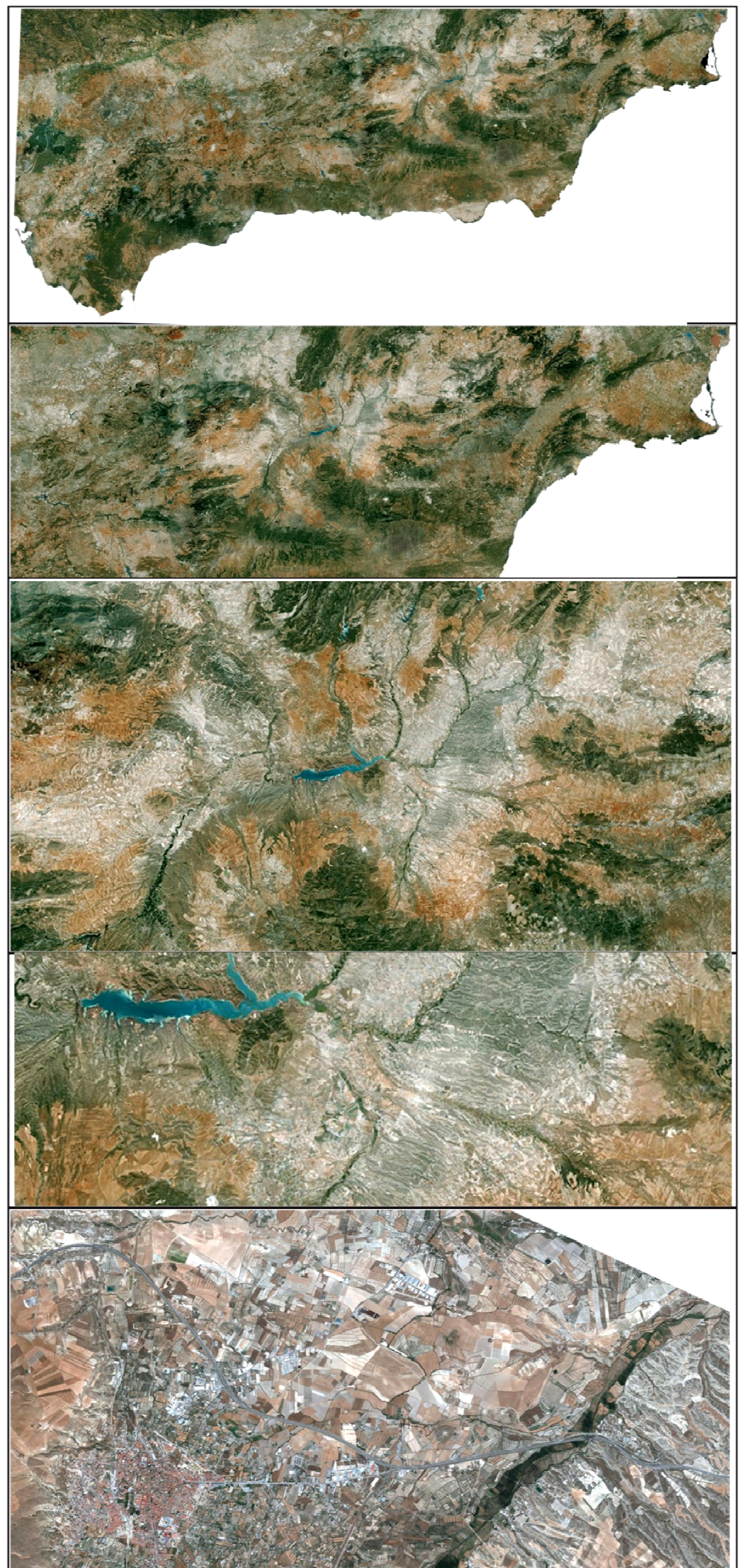
2.5.3 Cartografía descriptiva física MDT

O

Hiperescala A. La escala regional

○

Hiperescala B. La escala del paisaje

O

Hiperescala C. La escala comarcal

0

Hiperescala D. La escala local

O

Hiperescala E. La escala humana

Cartografía descriptiva física. MDT

Elaboración propia a partir de cartografía de la Junta de Andalucía y digitalizada en ArcGis
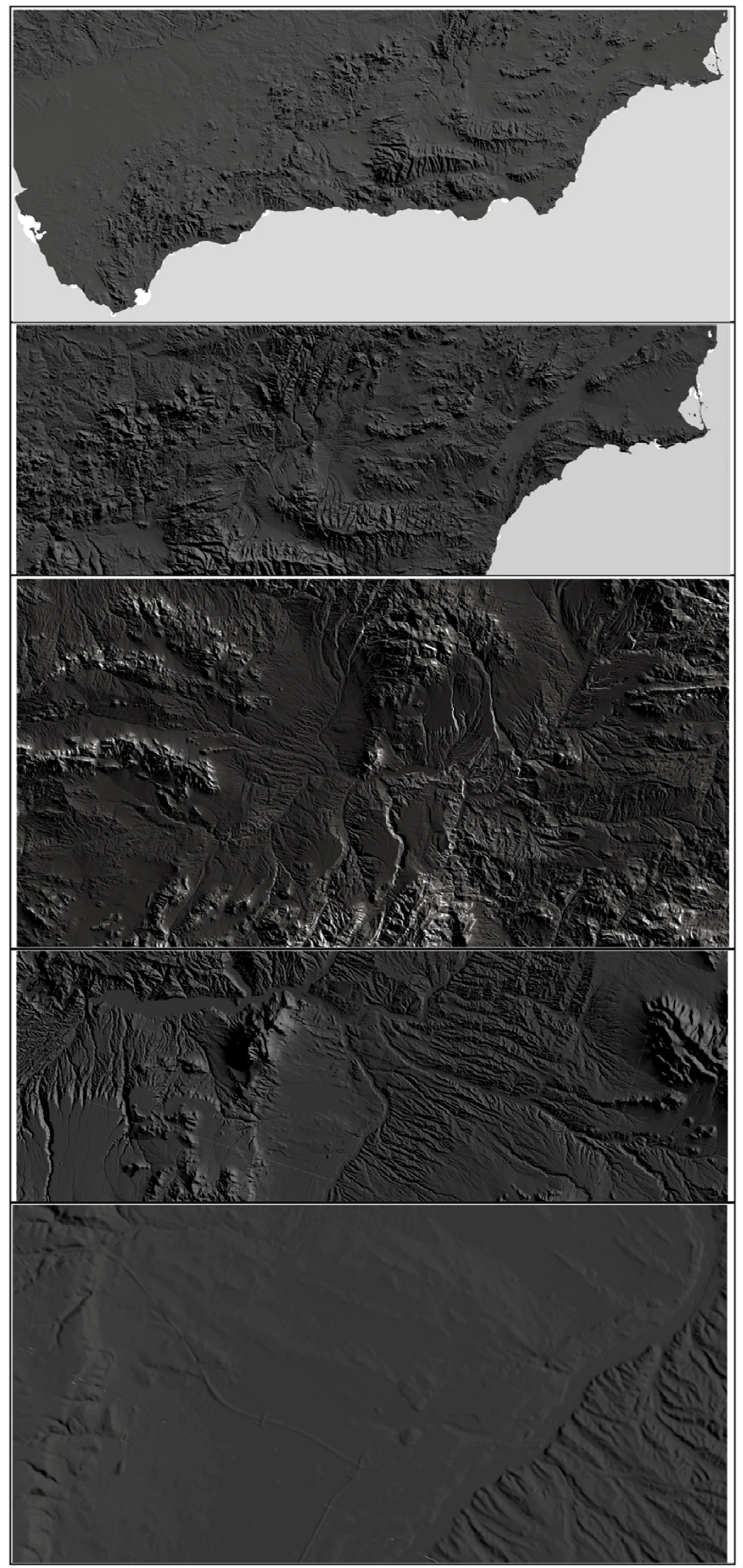
으

Hiperescala A. La escala regional

은 $50 \mathrm{~km}$

Hiperescala B. La escala del paisaje

은

Hiperescala C. La escala comarcal

은

Hiperescala D. La escala local

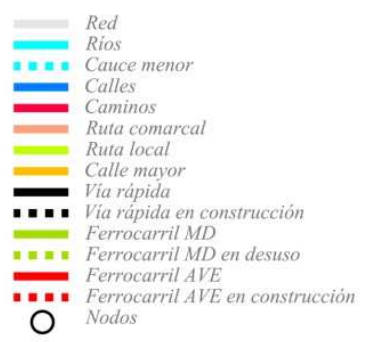

○

Hiperescala E. La escala humana
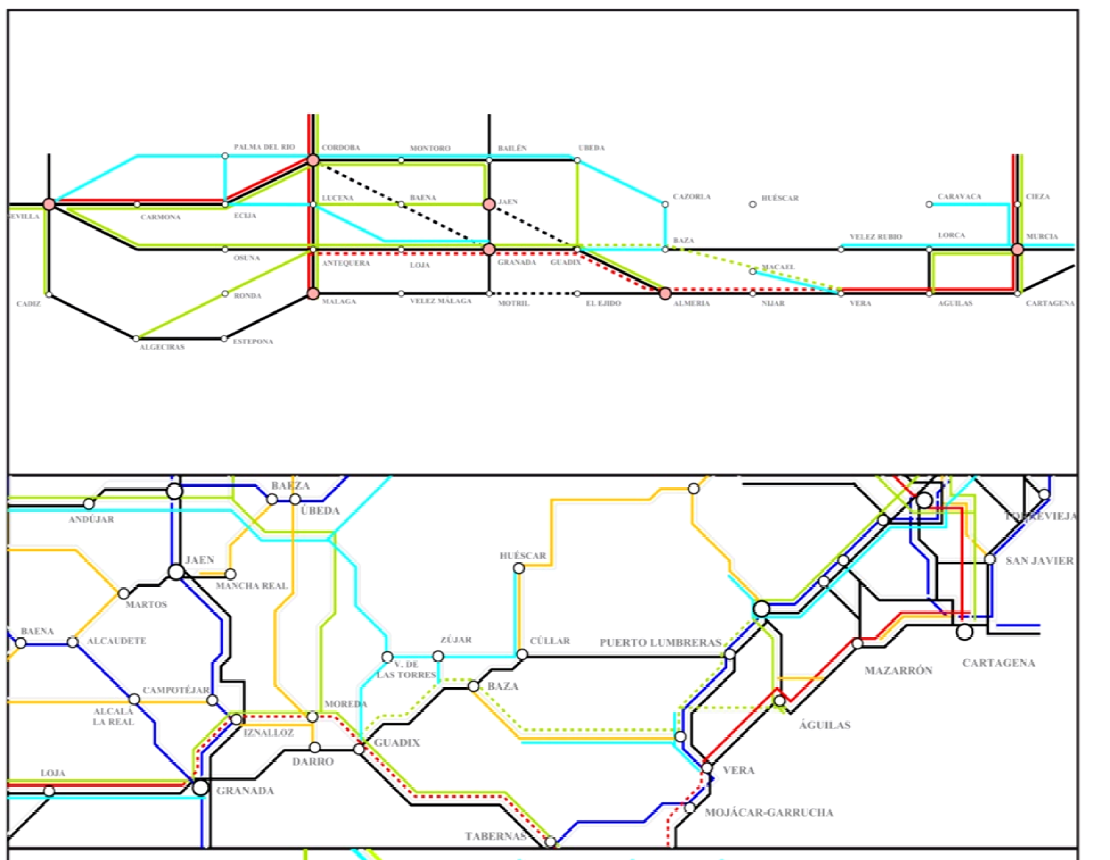
2.5.5 Cartografía proyectiva física ESTRUCTURA Y POBLACIÓN

$\underline{0}$

Hiperescala A. La escala regional

○

Hiperescala C. La escala comarcal
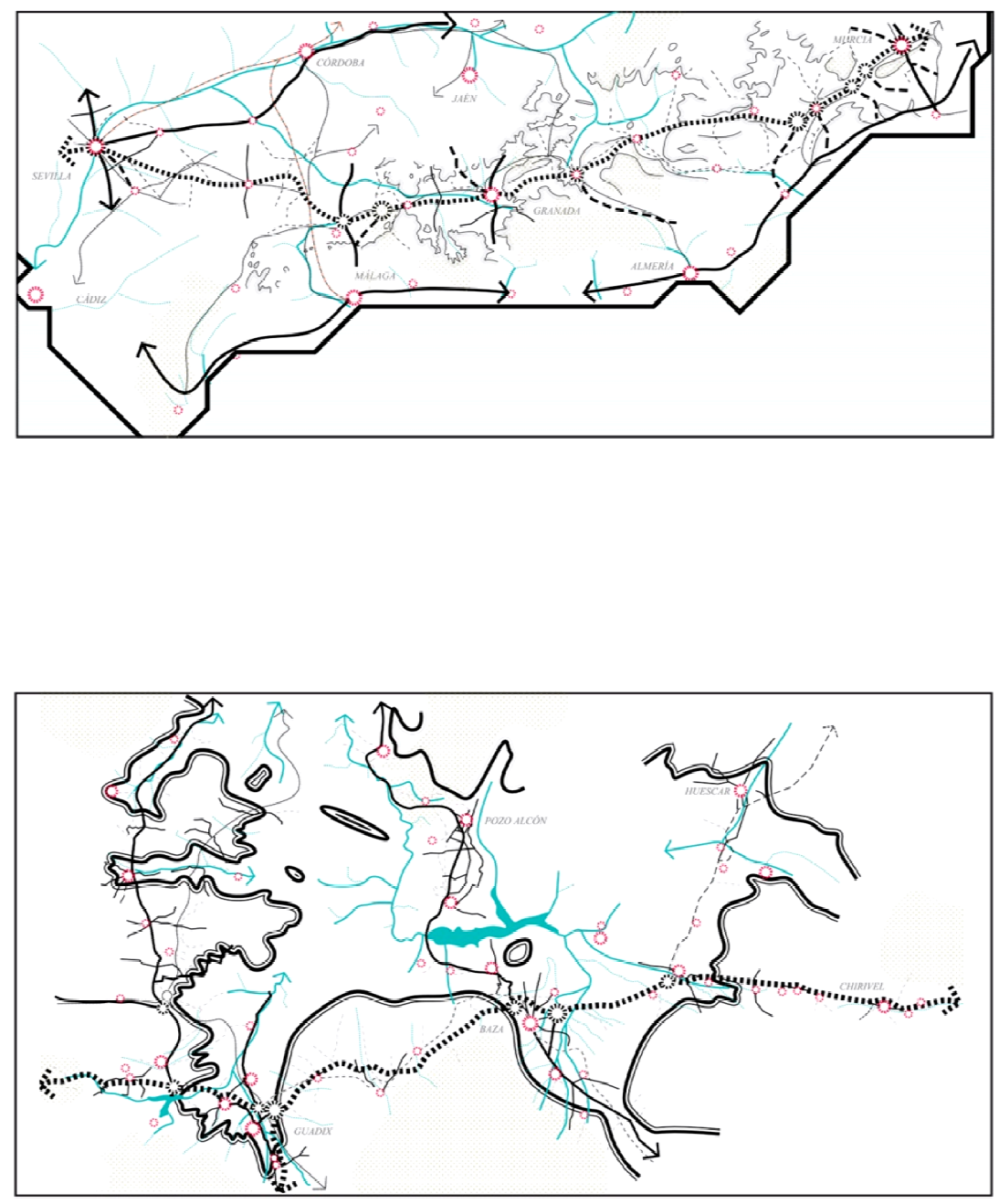

$\underline{0}$

Hiperescala E. La escala humana

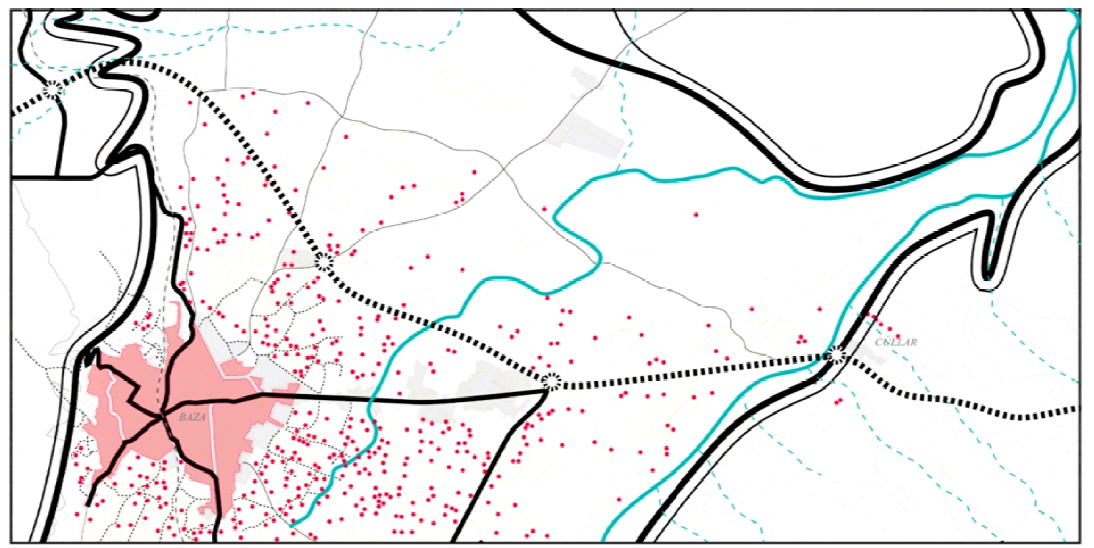

111 Corredor Trazado ferrocarril AVE

1- Corredor trans. continuo mayor

- Corredor trans. continuo menor
$\because$ - Puerta territorial viaria $\approx$ Fronteras fisicas

Puerta territorial ferroviaria

Núcleon de población
Edificación dispersa

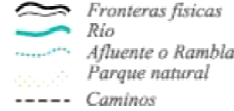
Parque natural Caminos

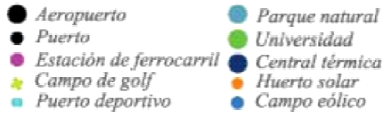

- Cantera o mina Poligono industrial - Parque empresarial

Cartografía proyectiva física. ESTRUCTURA Y POBLACIÓN

Elaboración propia a partir de cartografía descriptiva física 
2.5.6 Cartografía proyectiva física ESTRUCTURA Y ECONOMÍA

\section{$\underline{0}$}

Hiperescala A. La escala regional

\section{0}

Hiperescala C. La escala comarcal
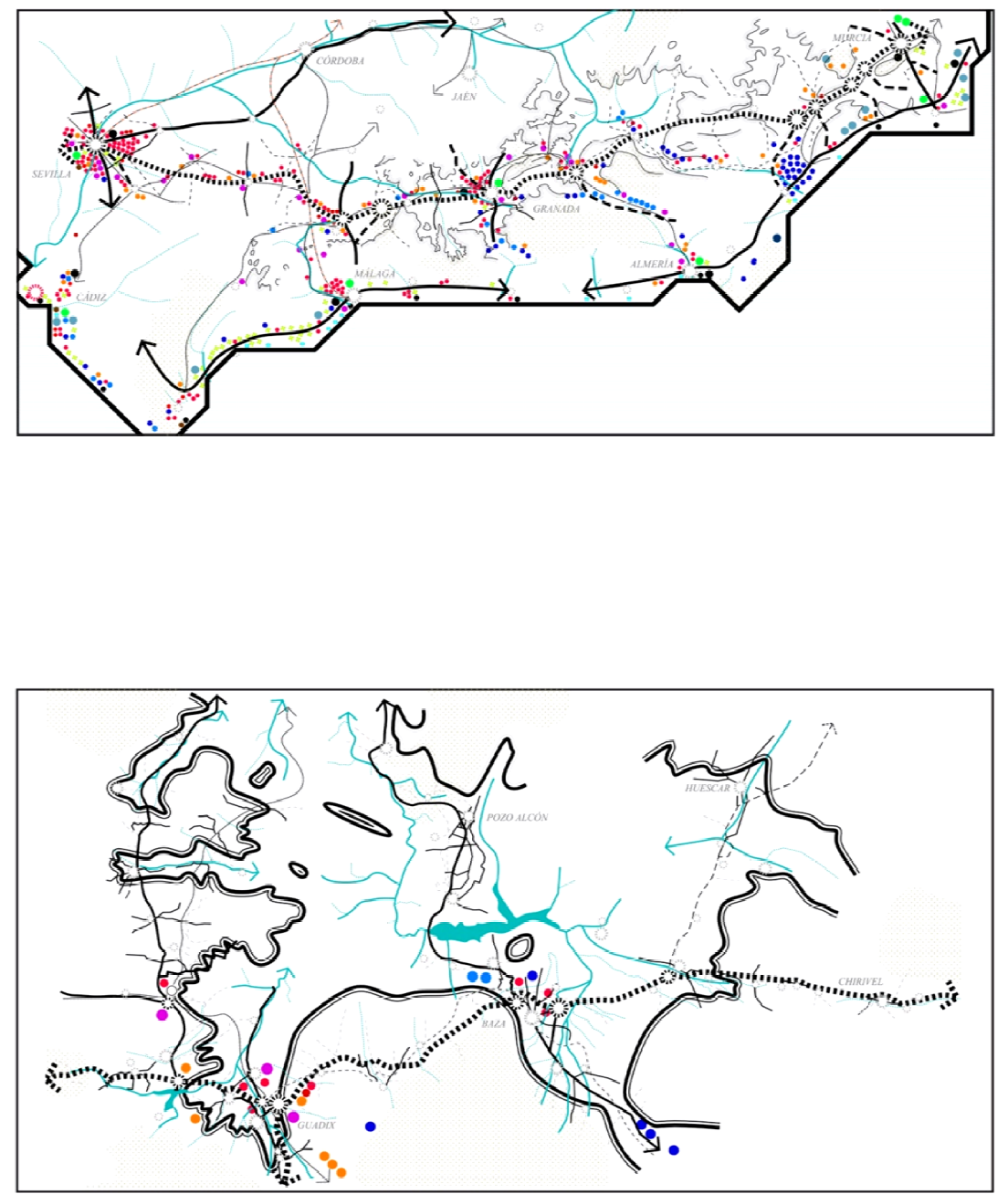

$\underline{0}$

Hiperescala E. La escala humana

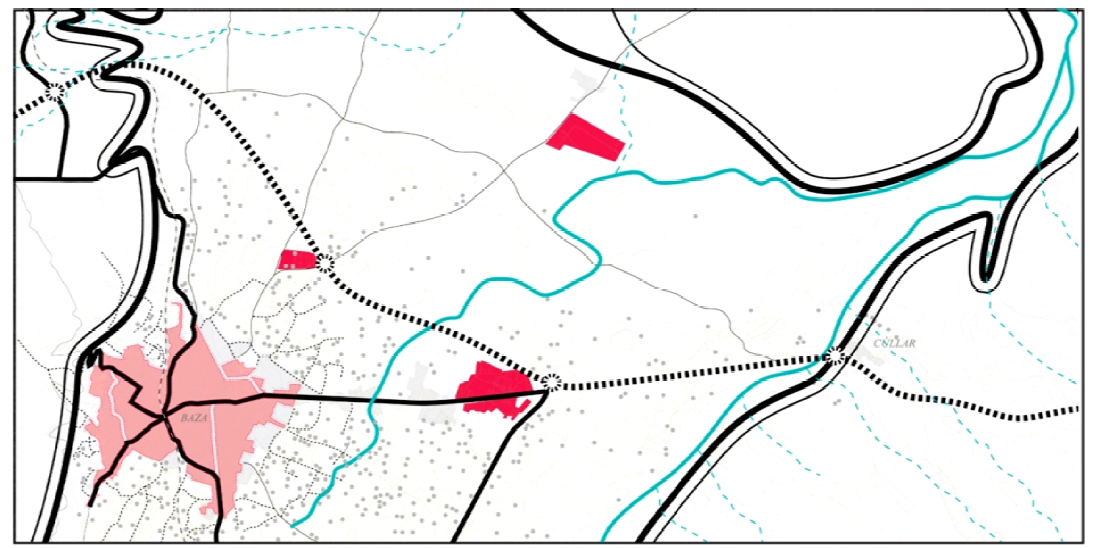

111 Corredor —_- Trazado ferrocarril AVE

11 Corredor trans. continuo mayor
$-1-$ Corredor trans, no continuo mayor
-

Corredor trans. continuo menor
-* Corredor trans, no contimuo menor
Puerta ferritorial viaria
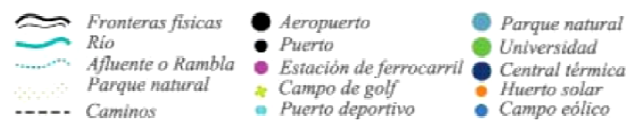

* Campo de golf

- Cantera o mina

Poligono industrial

Parque logistico

Cartografía proyectiva física. ESTRUCTURA Y ECONOMÍA

Elaboración propia a partir de cartografía proyectiva física: estructura y población y de datos de Google Maps 


\subsubsection{Cartografía proyectiva diagramática CENTRALIDADES}

\section{$\underline{0}$}

Hiperescala A. La escala regional

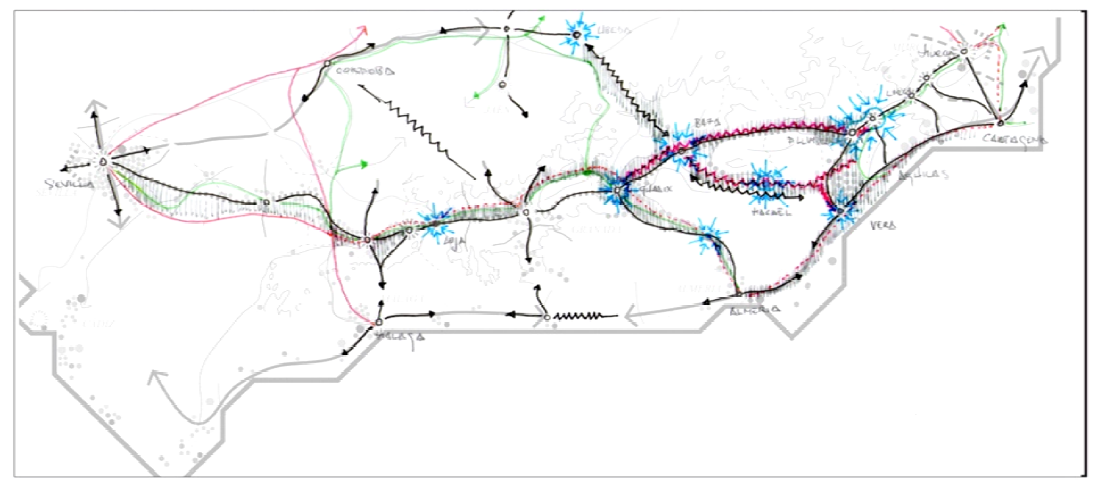

\section{O}

Hiperescala C. La escala comarcal

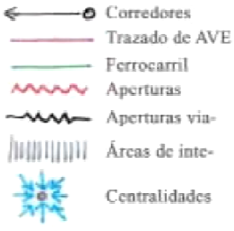

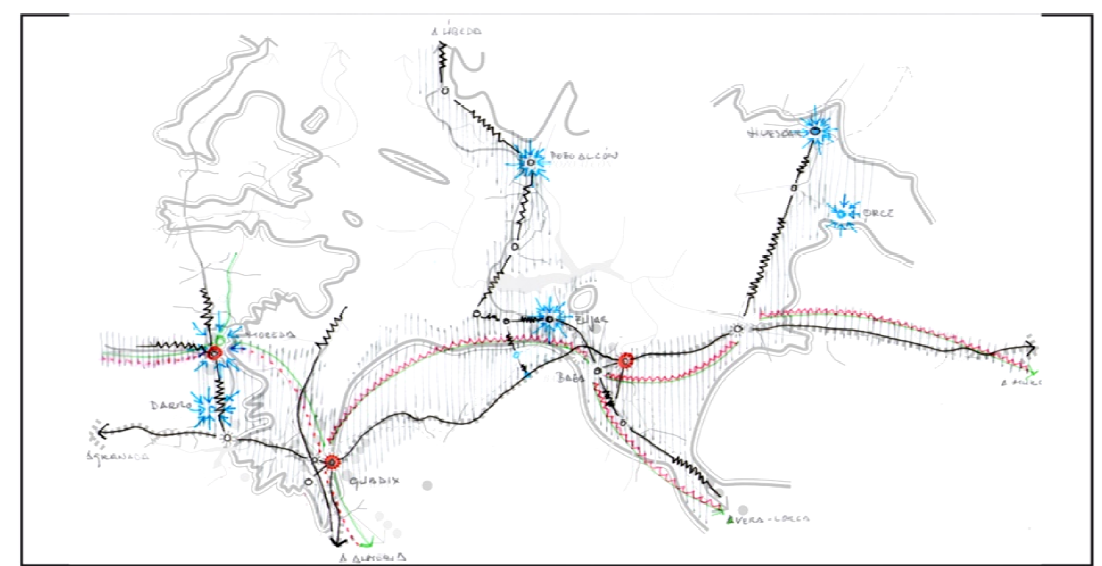

Cartografía proyectiva diagramática. CENTRALIDADES

Elaboración propia a partir de cartografía proyectiva física

\section{RESULTADOS}

Tras todo el proceso se consigue cartografiar el territorio de forma novedosa independientemente del ámbito de trabajo que se utilice, llegando a ser desvelados aquellos lugares que jugarán un papel decisivo en el desarrollo económico y social del territorio. No obstante, utilizando un mismo criterio gráfico podemos llegar a representar hasta un par clave encuadre-escala limitado, a partir del cual se hace necesario incrementar estos criterios con otros complementarios para poder generar cartografía útil, sobre todo en las escalas locales y humanas.

Se puede decir que cualquier territorio, en su "punto de partida", posee intrínsecamente los elementos clave (materiales, agua, clima, trazas, direcciones, historia, hábitats, sociedades, economías, caminos, topografía, vegetación, agriculturas,...) para desvelar "el proceso inicial" de sus líneas de desarrollo.

Se puede resumir con la generación de una matriz cartográfica informativa que nos ayuda a la hora de proyectar el territorio: 


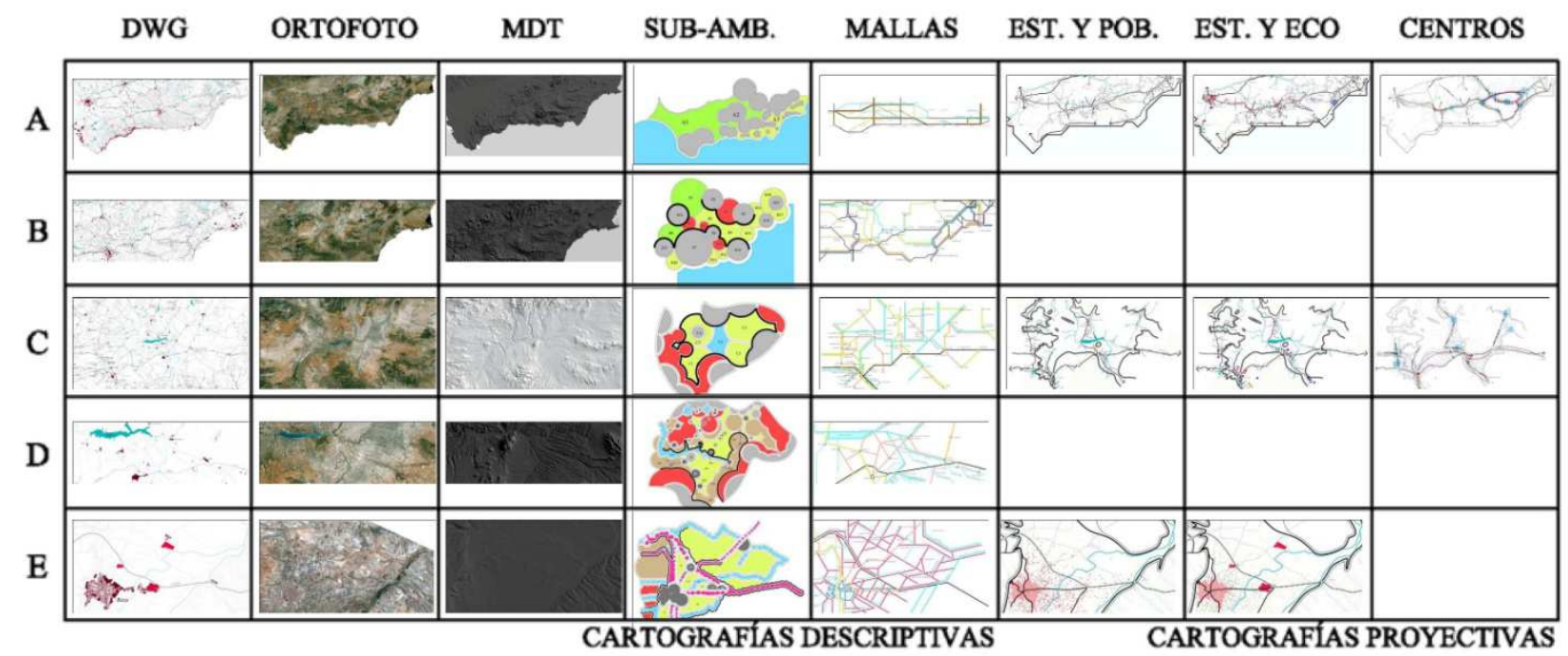

\section{DISCUSION Y CONCLUSIONES}

Para cada ámbito de estudio el encuadre y las escalas de visión y de representación son variables, pero existe un par clave que lo define. Se desvela que de las cinco hiperescalas estudiadas, son tres las que forman un par clave con su encuadre, estas son al hiperescala $A$, (regional), hiperescala C, (comarcal) e hiperescala E, (hábitat). Tanto la hiperescala B, (paisaje) como la hiperescala D, (local), son dos encuadres englobados en su inmediato superior e inferior, quedando definidos y supeditados por ellos. Esta forma de cartografiar el territorio puede contribuir en la toma de decisiones respecto a los trazados de las estrategias de comunicación de carácter global ofertando, en una fase intermedia en el proceso de planificación territorial, oportunidades y plusvalías que deben ser consideradas para definir el trazado definitivo de estos grandes proyectos continentales.

Las actuales relaciones mediante autovías que unen Andalucía con Murcia y que pasan, casi sin tomar tierra, por estas comarcas, no han sido suficientes para hacer de esta subregión un lugar de unión entre el levante y el interior andaluz. Para el desarrollo económico de la zona se detecta que es necesaria la unión de la Hoya de Guadix - Baza con Lorca así como con la comarca del mármol hasta Vera, mediante ferrocarril. Por todo ello se enuncia que el trazado del corredor mediterráneo por el litoral de la península puede contribuir al desarrollo de áreas fuertemente deprimidas, si a su paso por el territorio refuerza estas áreas locales mediante nuevas relaciones interiores, generación de redes menores, explotación de recursos naturales, localización de centralidades y encrucijadas.

\section{RECONOCIMIENTOS}

Esta reflexión debe su desarrollo a las inquietudes transmitidas en el tema y el territorio concreto, por parte del catedrático de urbanismo D. José Luis Gómez Ordóñez, del profesor D. Alejandro Grindlay Moreno y por el profesor D. Juan Luis Rivas Navarro, mis agradecimientos a los tres por su apoyo.

\section{BIBLIOGRAFÍA}

GÓMEZ ORDÓÑEZ, J. L. (2000). Estrategias para la ordenación territorial del Sudeste ibérico: horizontes para una periferia. Biblio 3W. Revista Bibliográfica de Geografía y Ciencias Sociales, 257. Universidad de Barcelona.

DEMATTEIS, GIUSEPPE. (1999). En la encrucijada de la territorialidad urbana. En DEMATTEIS, G. et al. I futuri de la città. Tesi a confronto, Franco Angeli, Milán.

LABORATORIO DE URBANISMO DE BARCELONA. (1981). La identitat del territori català: les comarques. Quaderns de Arquitectura y Urbanismo (Barcelona). 
MAGNAGHI, ALBERTO. (2000). I/ progetto locale. Torino: Bollati Boringhieri SCOT DU MONTPELLIER. (2006). Schéma de cohérence territoriale.

SABATE BEL, J. (1999). Plan Insular de Ordenación del Territorio, PIOT.

VIGANÒ, P. (1999). La città elementare. Virginia: Skira.

DE SOLÀ-MORALES, M. (2008). De cosas urbanas. Barcelona: Gustavo Gili SL.

PARCERISA BUNDÓ, J., RUBERT DE VENTÓS, M. (2000). La ciudad no es una hoja en blanco. Hechos del Urbanismo. Chile: Ediciones ARQ, SL.

HARVEY, D. (2000). Espacios de esperanza. Edinburgh: University Press. 